\title{
CLEAN INTERMITTENT SELF-CATHETERIZATION IN THE ELDERLY
}

\author{
CAROL J. BENNETT, M.D. \\ ANANIAS C. DIOKNO, M.D. \\ From the Department of Surgery, Section of Urology, \\ University of Michigan Medical Center, \\ Ann Arbor, Michigan
}

\begin{abstract}
There has been some doubt as to whether or not the elderly patient can successfully master and comply with clean intermittent self-catheterization in the treatment of their bladder dysfunctions. We recently reviewed our experience with intermittent self-catheterization in patients sixty years of age and older to determine whether or not this was an acceptable alternative to other methods of urinary drainage. Our retrospective analysis of 65 patients between the ages of sixty and eighty years revealed that the elderly patient had little difficulty mastering the technique of intermittent self-catheterization. Complications were minimal and in general correctable. The catheterization program was successful in 94 per cent of the patients in our series.
\end{abstract}

Clean intermittent self-catheterization (ISC), as popularized by Lapides $e t a l .^{1}$ is now a wellestablished method of bladder emptying. This technique involves regular and frequent catheterization to prevent bladder over-distention and progressive renal deterioration, while at the same time allowing the bladder wall to regain its muscle tone. This method is easily learned and has proved to be invaluable adjunctive therapy for patients with a variety of bladder-emptying dysfunctions. Concern has persisted that this method may be impractical in patients of extreme ages. Kass, McHugh, and Diokno $^{2}$ have previously reported the success of ISC in children less than six years of age with various bladder dysfunctions. Herein we present our data on 65 consecutive patients sixty years or older registered in our unsterile intermittent self-catheterization program.

\section{Material and Methods}

The records of 65 patients aged sixty years or older were reviewed. No other form of urinary drainage was employed. Initial evaluations, in most cases, included cystometrography, periuretheral sphincter electromyography, and cystourethroscopy. The indications for intermittent catheterization, as well as any concomitant debilitating medical illness, were determined. All patients were seen at regular intervals in our clinic and followed up with serial physical examinations, urinalysis and/or culture, indicated laboratory tests, and excretory urograms. All complications were identified and analyzed.

Results

There were 34 males and 31 females in our series. Of the 34 males, ages ranged from sixty to seventy-five years, with an average age of sixty-five. The 31 females ranged in age from sixty to eighty years, with an average age of sixty-nine. The patients were followed from three months to as long as ten years.

The most common indication for intermittent catheterization in females was nonneurogenic, atonic, or decompensated bladder, accounting for 16 patients or 51 per cent (Table I). The diagnosis of an atonic or decompensated bladder was made on the basis of large residual urine and a negative bethanechol super sensitivity test. There were 11 patients $(35 \%)$ with neurogenic bladder dysfunctions. 
TABLE I. Female patients

\begin{tabular}{lcr}
\hline & \multicolumn{2}{c}{ Patients - } \\
\cline { 2 - 3 } \multicolumn{1}{c}{ Indications } & No. & \multicolumn{1}{c}{$\%$} \\
\hline $\begin{array}{l}\text { Decompensated bladder } \\
\text { Uninhibited neurogenic }\end{array}$ & 16 & 51.7 \\
$\quad$ bladder with decompensation & 4 & 13.0 \\
Motor paralytic bladder & 3 & 9.6 \\
Sensory paralytic bladder & 3 & 9.6 \\
$\begin{array}{l}\text { Reflex neurogenic bladder } \\
\text { Postoperative bladder }\end{array}$ & 1 & 3.2 \\
$\quad \begin{array}{l}\text { procedure } \\
\text { Postoperative gynecologic }\end{array}$ & 3 & 9.6 \\
$\quad$ procedure & & \\
$\quad$ ToTALS & 1 & 3.2 \\
\hline
\end{tabular}

Atonic bladder was the most common cause requiring intermittent catheterization in males (Table II). In the group of 16 patients with nonneurogenic hypotonic bladder $(47 \%)$, one-half were secondary to persistent retention in spite of adequate resection of the obstructing benign prostate gland. Five of the male patients $(15 \%)$ had documented obstructive uropathy but either were not surgical candidates or declined operative therapy. Thirteen patients $(38 \%)$ had neurogenic bladder dysfunctions.

Fifty-seven per cent of our 65 patients had associated debilitating disease. The most common concomitant problem seen in 32 per cent of our patients were cerebrospinal disorders such as spinal cord injury, multiple sclerosis, and Parkinson disease leading to musculoskeletal disturbance and neurogenic bladder dysfunction. Arthritis and degenerative joint disease was seen in 10 per cent of our patients. Many of these patients on initial evaluation were noted to have poor hand dexterity as a consequence of their arthritis but with careful instruction were able to master the ISC technique. One patient, an eighty-year-old woman, had both arthritis and severe cataracts but had no trouble learning to catheterize by palpation and has now been in our ISC program for over a year.

Table III illustrates complications in our series. Problems with intermittent catheterization were encountered by 9 of our patients $(14 \%)$. In 3 patients urethral strictures developed, two of which were exacerbation of a pre-existing stricture. All 3 patients responded to urethral dilatation and were able to continue their catheterization program. Two patients had periodic difficulty inserting the straight catheter
TABLE II. Male patients

\begin{tabular}{lrr}
\hline & \multicolumn{2}{c}{ Patients } \\
\cline { 2 - 3 } \multicolumn{1}{c}{ Indications } & No. & $\%$ \\
\hline Decompensated bladder & 16 & 47 \\
Obstructive uropathy & 5 & 15 \\
Reflex neurogenic bladder & 4 & 12 \\
Uninhibited neurogenic bladder & & \\
$\quad$ and motor paralytic bladder & 4 & 12 \\
Motor paralytic bladder & 3 & 9 \\
Autonomous neurogenic & & \\
$\quad$ bladder & 1 & 2.5 \\
Spinal shock bladder & 1 & 2.5 \\
$\quad$ Totals & 34 & 100.0 \\
\hline
\end{tabular}

TABLE III. Complications with ISC

\begin{tabular}{lc}
\hline \multicolumn{1}{c}{ Complication } & No. \\
\hline Urethral stricture & 3 \\
Unable to insert straight catheter & 2 \\
Poor patient compliance & 3 \\
Persistent urinary incontinence & 1 \\
TotALs & 9 \\
\hline
\end{tabular}

because of prostatic calculi and the anatomic configuration of the prostatic fossa. With the switch to Coudé-tip catheter, both were able to continue ISC without difficulties.

Intermittent catheterization was discontinued in 4 patients. Poor compliance was exhibited by 2 patients and by the husband of 1 patient who was assisting his wife with the catheterization. In 1 patient, a seventy-fiveyear-old woman with an original diagnosis of decompensated bladder, severe stress incontinence developed following abdominoperineal resection and hysterectomy for cloacogenic carcinoma. Incontinence persisted in spite of bladder suspension surgery, and intermittent catheterization was abandoned.

The catheterization program was successfully utilized by 61 patients or 94 per cent of the patients in the series. Although the majority have bacteriuria and/or pyuria, in no patients did pyelonephritis, sepsis, or renal calculus develop while on the program.

\section{Comment}

Prior to the introduction of ISC by Lapides $e t$ al. in $1971,{ }^{1}$ the alternative treatments for uncorrectable vesical dysfunctions with large residuals associated with urinary tract infection, were urinary tubeless diversion, sphincterotomy, 
indwelling urethral catheter, or suprapubic cystostomy. ${ }^{3-6}$ Urinary diversion, whether supravesical or vesical, is associated with the potential complications of pyelonephritis, stone formation, and long-term renal function deterioration. ${ }^{7}$ Sphincterotomy necessitates condom catheter drainage and can be complicated by penile ulceration and infections. Indwelling urethral catheterization has proved less than ideal because of long-term problems with vesical stones, urethritis, urethral erosion, and inadvertent catheter occlusion. While suprapubic tubes are not associated with urethritis and erosion, they are still potential sources of vesical calculi and are subject to occlusion. In addition, the aforementioned methods of urinary drainage, with the exception of an indwelling urethral catheter, require an operation which the elderly patient is less likely to tolerate.

Our review of intermittent self-catheterization in the elderly reinforces our belief in ISC as a viable alternative for treating the elderly with urinary retention. Not only is the method safe and effective in patients ranging in age from five to seventy-four years as reported previously, ${ }^{8}$ but also when the elderly are examined as a separate group, they perform remarkably well. ISC is a legitimate alternative to indwelling catheters or other forms of urinary diversion. ISC complications are relatively minor, and the technique is easily mastered even by patients with significant disability. It is safe, well tolerated, and associated with a high compliance rate.

Ann Arbor, Michigan 48109

(DR. BENNETT)

\section{References}

1. Lapides J, Diokno AC, Silber SJ, and Lowe BS: Clean intermittent self catheterization in the treatment of urinary tract discase, Trans Am Assoc Genito-Urin Surg 63: 92 (1971).

2. Kass EJ, McHugh T, and Diokno AC: Intermittent catheterization in children less than six years old, J Urol 121: 792 (1979).

3. Edwards RH, Rurko H, Rhany R, and Trapp D: Cineradiographic analysis of neurogenic bladder in children, ibid 100: 290 (1968).

4. Smythe CA: External sphincterotomy in the management of the neurogenic bladder: a preliminary report, ibid 96: 310 (1966).

5. Boyarsky $S$ : Recent advances in neurogenic bladder, ibid 102: 53 (1969).

6. Walker $\mathrm{W}$, and Wise $\mathrm{M}$ : Ureteroileostomy in management of neurogenic bladders in the adult, ibid 102: 325 (1969).

7. Raz S, and Bradley W: Neuromuscular dysfunction of the lower urinary tract, in Harrison JH, et al (Eds): Urology, 4th ed, Philadelphia, WB Saunders Co., 1979.

8. Lapides J, Diokno AC, Lowe BS, and Kalish MD: Followup on unsterile, intermittent self-catheterization. J Urol 111: 184 (1974). 